\title{
A confluência literatura / educação: suas realizações históricas
}

Roberto Acízelo Quelha de Souza ${ }^{a}$

\begin{abstract}
Resumo
$O$ artigo caracteriza as realizações históricas da confluência literatura / educação, mostrando como a cultura literária sucessivamente se articulou com os conceitos de humanidades, nacionalidade, literariedade e diversidade.
\end{abstract}

Palavras-chave: humanidades; nacionalidade; literariedade; diversidade. 
O que a modernidade entende por literatura consiste num corpo de escritos de natureza estética, isto é, liberados de qualquer objetivo pragmático, e que, nessa condição, concretizam o ideal que se convencionou chamar "a autonomia da arte". No entanto, se retornarmos à fonte talvez mais nítida e pioneira da formulação desse princípio moderno da autonomia estética, sempre encontramos, nem que seja como uma espécie de concessão, o reconhecimento de que a arte afinal serve para alguma coisa. Vejamos a passagem: "Bela arte [...] é um modo-de-representação que por si mesmo é final e, embora sem fim, no entanto propicia a cultura dos poderes-da-mente para a comunicação social" (KANT, 1974, p. 339). Talvez se possa senão se deva - entender essa "cultura dos poderes-da-mente para a comunicação social" apenas como um giro mais tortuoso para dizer simplesmente educação. Assim, a arte em geral, e a literatura em particular, teriam a ver com educação, mesmo na modernidade, quando pelo menos em tese os produtos estéticos deveriam justificar-se por critérios que não os subordinassem a qualquer outra esfera das ações.

A partir dessa constatação inicial, tentemos analisar diversos modos históricos por que a literatura se conjugou com a educação.

\section{2}

Na Grécia Antiga - mais de dois mil anos, portanto, antes da ideia de autonomia da arte -, a poesia se justificava por seu valor gnômico: "Homero educou a Grécia", reza a frase atribuída a Heródoto, e assim os poetas figuravam entre os mestres da verdade, ao lado dos adivinhos e dos reis-magistrados. Eco longínquo dessa concepção encontramos ainda em Isidoro de Sevilha (século VI-VII d.C.), cujas Etimologias, espécie de proto-enciclopédia medieval, tratam da figura do poeta no mesmo livro em que caracterizam os magos, as sibilas, os deuses pagãos. Liam-se - ou se ouviam - então os poetas não pela gratuidade do que diziam, mas, muito ao contrário, por suas revelações e ensinamentos. Espécie de suporte rítmico e bem embalado para a circulação dos mitos etiológicos e das regras para se viver, os poemas constituíam fonte de conhecimento e 
sabedoria, respondendo, pois, pela formação cultural dos antigos helenos. A partir de certo momento, além da poesia outras práticas letradas - a oratória, a história e a filosofia - passariam a integrar tal fonte, que, devidamente assimilada, concretizaria a paideia, isto é, a educação do indivíduo, a plenitude de sua formação cultural.

Esse conceito de formação integral do homem, por via da cultura conjugada da poesia, da oratória, da história e da filosofia, embora profundamente enraizado na mentalidade antiga, tornou-se estranho para os tempos modernos, talvez sobretudo por prescindir do concurso de saberes especializados que hoje chamaríamos técnicos e científicos. A palavra grega em que encontrou expressão - paideia -, por sinal, indicia tal estranheza, dadas as dificuldades de tradução que suscita. Usualmente a traduzimos por formação, mas, na opinião de especialistas, não há palavra no vocabulário das línguas ocidentais modernas que consiga preservar a plenitude do conceito veiculado pelo termo grego. No entanto, se recorrermos ao latim, talvez encontremos uma correspondência que nos seja esclarecedora. Vejamos:

Segundo Aulo Gélio, um erudito romano do século II d.C., entre seus compatriotas menos cultos a palavra latina humanitas (isto é, humanidade) se empregava com o mesmo sentido do grego filantropia (isto é, explica ele, "um certo tipo de benevolência para com todos os homens indistintamente"); no entanto, esclarece que a correspondência correta do latim humanitas seria antes com o grego paideia, palavra que, por sua vez, também poderia traduzir-se em latim por eruditio (erudição) ou institutio in bonas artes (instrução em saberes bons, isto é, em conhecimentos ao mesmo tempo proveitosos, honestos e úteis). Assim, ainda conforme a explicação de Aulo Gélio, a erudição e a instrução nos bons saberes, sendo facultada exclusivamente ao homem, e a nenhum outro ser animado, seria por isso mesmo chamada em latim humanitas, nome do atributo que define o homem, ou seja, a sua humanidade. ${ }^{1}$ Desse modo, a expressão latina studia humanitatis (estudos da humanidade) se usa pelo menos desde o tempo de Cícero, prolongando-se seu emprego pela Idade Média, quando, a partir do século V, passa a designar o conjunto das disciplinas escolares básicas, as chamadas sete artes liberais, tradicionalmente divididas em dois conjuntos, o trivium, constituído por gramática, retórica e lógi- 
2 Nas línguas modernas, com o significado de "cultura humanística" se usa a forma do plural por um acidente comum na deriva do latim. É que a palavra resultou de uma redução do sintagma latino studia humanitatis; o sentido se concentra no termo determinante humanitatis, que, não mais tomado como genitivo, passa a ter o $s$ final interpretado como marca morfológica de plural; assim, studia humanitatis, em vez de estudos da humanidade resultou simplesmente em humanidades. ca, e o quadrivium, integrado por música, aritmética, geometria e astronomia (SOUZA, 1999, p. 21-22; SOUZA, 2006, p. 153-154).

Ora, a referida palavra latina passou para as línguas modernas com ambos os significados discernidos por Aulo Gélio. Desse modo, em português, por exemplo, taxamos uma atitude cruel como falta de humanidade, quer dizer, de benevolência, de amor ao semelhante; mas, desde que pluralizada - humanidades ${ }^{2}$-, a palavra nomeia certo conjunto de saberes, constitutivos da assim chamada cultura humanística. Humanísti$c a$, já vimos, porque atributo exclusivo do homem, mas também porque extensível a todos os homens, independentemente de seus interesses por saberes especializados, isto é, técnicos ou científicos. Assim, embora entre as sete artes liberais figurem matérias que nossas concepções modernas incluiriam no rol das ciências - astronomia, geometria, aritmética -, enquanto integrantes desse "currículo" antigo faltam-lhes as propriedades das ciências modernas: por um lado, desconhecendo o experimentalismo, têm por base o princípio de autoridade; por outro, sem compromisso com alta especialização, constituem parcela da cultura geral, isto é, aquela comum a todos os homens, e desse modo trata-se, por exemplo, não da astronomia para formar astrônomos, mas para integrar o repertório de conhecimentos indispensáveis a todos os homens cultos. Naturalmente, por "todos os homens", no contexto antigo em que emerge e circula o conceito, entenda-se "homens livres", isto é, aqueles que, sendo livres, por isso mesmo têm acesso às artes ditas liberais, que se opõem às artes chamadas mecânicas, próprias dos escravos e demais trabalhadores braçais.

Em síntese, tentemos articular melhor essas noções: estudos da humanidade, erudição, instrução em boas artes, artes liberais; humanidades, cultura humanística, educação liberal: isto é, conjunto integrado de conhecimentos concebidos idealmente como de interesse comum, e por isso consubstanciados não em códigos especializados, mas na linguagem comum, ou seja, nas letras, termo histórico que, anterior à moderna distinção entre ciência e literatura, compreende as mais diversas manifestações discursivas: cartas, tratados, poemas, narrativas, sermões, etc., etc.

Agora, voltemos ao nosso ponto, a confluência literatura / educação. Nessa primeira de suas realizações históricas, para sermos mais exatos, não temos propriamente literatura - conceito, como veremos, ainda por ser inventado -, porém 
a ideia mais abrangente de letras, que, por sua vez, converge com a de humanidades; trata-se a rigor de conceitos sobrepostos, mas, simplificando, podemos dizer que as letras, então, ensinam as humanidades.

A partir, contudo, de meados do século XVIII, segunda uma tendência que se consolidaria no XIX, as letras aos poucos vão-se afastando do universalismo das humanidades, para se colocarem a serviço das particularidades nacionais.

Essa transição se encontra amplamente documentada. Observa-se, por exemplo, que um velho esteio das letras humanísticas, os tratados de retórica e poética, começam a derivar para o âmbito do nacional. Vejamos dois exemplos brasileiros do fato: escrito em 1852 e publicado em 1869, Junqueira Freire atribuiu ao seu pequeno tratado o título de Elementos de retórica nacional; e o padre Lopes Gama, na profissão de fé pedagógica com que inicia o seu - aliás, intitulado Lições de eloquência nacional -, assim se pronuncia: "[...] a Eloquência, que temos de estudar, não é a Eloquência em geral, senão a Eloquência Nacional, é a Eloquência aplicada ao nosso idioma, aos nossos usos, e costumes, à nossa legislação, à nossa forma de Governo" (GAMA, 1846, v. 1, p. i). Mas, mesmo com essa explícita concessão ao nacionalismo, os tradicionais compêndios, tratados ou manuais de retórica e poética, por seu constitutivo compromisso com a perspectiva universalista das humanidades, acabam perdendo a hegemonia no sistema de ensino, vendo-se preteridos por um novo gênero, as histórias literárias. Essas, por definição, assumem como fundamento a restrição ao campo da cultura nacional, o que, entre nós, leva Sílvio Romero, por exemplo, a incluir o capítulo "Nacionalismo literário" num livro seu de 1880, A literatura brasileira e a crítica moderna, bem como a afirmar, no prólogo de sua História da literatura brasileira, de 1888: "A aplicação ao Brasil é a preocupação constante [...]" (ROMERO, 2001, v. 1, p. 51).

Ora, essa orientação nacionalista, de que oferecemos aqui uns poucos exemplos brasileiros, se não chegou a ser muito destacada em países como a Inglaterra e os Estados Unidos, tornou-se amplamente majoritária na Alemanha e nas nações latinas. E não se cingiu, naturalmente, às obras destinadas ao 
ensino de letras - compêndios de retórica e poética ou de história literária -, mas alcançou igualmente a poesia, a narrativa de ficção, o drama, chegando mesmo a fixar, como critério de valor, o grau maior ou menor de adesão dos produtos literários às particularidades de cada país, cuja geografia, história e sociedade caberia à literatura representar. Por isso, é nesse momento que se define a ideia de literatura nacional: não haveria assim propriamente $a$ literatura, mas sim culturas literárias diferenciadas segundo as nacionalidades, e daí noções como literatura brasileira, literatura portuguesa, literatura francesa, etc., etc., noções que, naturalizadas na sua apropriação pelo senso comum, logo se esvaziariam por completo de sua historicidade.

Por esse tempo, assim, o termo literatura começa a circular. Resultou de uma restauração erudita do latim litteratura, neologismo no tempo de Cícero (séculos II-I a.C.), sinônimo da palavra tradicional litterae (letras). Em português, seu registro mais antigo em dicionário data de $1727,{ }^{3}$ mas numa acepção não coincidente com a moderna: literatura lá se define como "erudição ou conhecimento das letras", tratando-se, pois, de um atributo do indivíduo letrado, do qual se poderia dizer, por exemplo, que "tem literatura". Com esse mesmo sentido a palavra aparece em sucessivas edições do Morais - 1823, 1831, 1844, 1858 -, o grande dicionário oitocentista da língua portuguesa, até que, somente a partir da edição de 1877-1878, assume o significado moderno que nos é familiar: "O conjunto das produções literárias duma nação, dum país ou duma época [...]" (SILVA, 1877-1878, v. 2, p. 244).

No entanto, no uso especializado, o termo suscitava definições divergentes. Para alguns, a extensão do conceito era ampla, abrangendo qualquer gênero de discurso escrito, e no limite até os gêneros orais. Entre nós, Sílvio Romero representou esse ponto de vista - "[...] para mim a expressão literatura [...] [c]ompreende todas as manifestações da inteligência de um povo: política, economia, arte, criações populares, ciências... e não [ ] somente as intituladas belas-letras [...]" (ROMERO, 2001, p. 61). -, ao passo que José Veríssimo defendeu a opinião oposta:

Trata-se de verbete do primeiro volume do suplemento do Vocabulário português e latino, de Rafael Bluteau, que constitui o nono volume da obra e saiu em 1727.
Literatura é arte literária. Somente o escrito com o propósito ou intuição dessa arte, isto é, com os artifícios de invenção e de composição que a constituem, é, a meu ver, literatura. [...] Esta é [...] sinônimo de boas ou belas-letras [...]. Nem se me dá da pseudonovidade [...] que o vocábulo literatura 
compreende tudo o que se escreve num país, poesia lírica e economia política, romance e direito público, teatro e artigos de jornal e até o que não se escreve, discursos parlamentares, cantigas e histórias populares, enfim autores e obras de todo o gênero (VERÍSSIMO, 1969, p. 10).

Observe-se, contudo, que, divergência à parte, essas definições coincidiam num ponto: a literatura, quer se tome o conceito em sentido amplo, quer em sentido restrito, se circunscreveria ao espaço nacional, sendo, por conseguinte, expressão de cada nacionalidade. Assim, voltando mais uma vez ao nosso ponto de partida - a confluência literatura / educação -, depois do longo período em que a cultura literária se via como a representação das humanidades, advém um tempo em que ela se quer tradução das nacionalidades.

\section{4}

A vacilação oitocentista entre os conceitos amplo e restrito de literatura, pelo menos nos meios mais identificados com o pensamento das vanguardas artísticas que se definiram entre 1880 e 1920, acabou pendendo para o segundo. Como queria Veríssimo, literatura, nesses meios, passou a definir-se como arte literária, isto é, como atividade autônoma, por isso habilitada a neutralizar o mais possível a transparência referencial própria da linguagem. Assim, a literatura se vê dispensada de qualquer compromisso que não seja com ela mesma: não representa as humanidades, tampouco as nacionalidades, à medida que, como postulava, em meados do século passado, um dos entusiastas dessas concepções novecentistas, "[...] para o escritor escrever é um verbo intransitivo [...]" (BARTHES, 1970, p. 33).

Ora, sem ser referência nem expressão, definida, ao contrário, por seu radical autocentramento, a literatura só teria de ser fiel ao seu próprio modo de ser, ou seja, à sua literariedade, palavra que, inventada no início do século $X X$, transpunha para o campo teórico-analítico-crítico o princípio orientador da prática de poetas e prosadores identificados com a ideologia estética das vanguardas artísticas.

Consagrada então a ideia de literariedade, se poderia supor que enfim a literatura se desconectava de qualquer finalidade que não fosse "[...] torna[r]-se pura e simples 
manifestação de uma linguagem que não tem por lei senão afirmar - contra todos os outros discursos - a sua existência abrupta [...]" (FOUCAULT, s.d., p. 393). Ainda assim, contudo, a literatura continuaria a exercer sua potência educativa; pelo novo status que reivindicava para si, embora renunciasse inteiramente a promover cultura geral ou formação ética, política e cívica, ela se reservava o papel de por assim dizer induzir uma nova sensibilidade estética, capaz de habilitar os indivíduos a superar preconceitos contra certas manifestações artísticas, em especial as da modernidade, de modo a fomentar o aparecimento de um público receptivo e capacitado à justa avaliação das obras de arte. Nesse sentido, lembremo-nos da frase atribuída a Oswald de Andrade - "A massa ainda comerá dos biscoitos finos que fabrico." 4 -, projetando no futuro uma recepção compreensiva para com seus experimentos, por força da ação pedagógica de sua própria arte. A literatura, assim, se reservaria o papel de ensinar a si própria, isto é, seria professora do atributo que a constitui e distingue, a literariedade.

Nessa missão - acrescente-se, para concluir -, o braço conceitual não seria mais a história literária nacionalista, porém a teoria da literatura, a nova disciplina novecentista resultante da sintonização dos estudos literários com “[...] o variadíssimo conteúdo da atividade literária própria da civilização e da cultura modernas [...]" (RODÓ, 1957, p.516), a materializar-se num "[...] livro de verdadeira iniciação literária, mas também de educação da sensibilidade estética e do gosto [...]" (RODÓ, 1957, p.516).

\section{5}

Mas a literariedade como eixo da confluência literatura / educação começa a tornar-se objeto de contestação sistemática por volta da década de 1960, num processo que culminaria nos anos de 1990. É que nesse lapso de tempo, no âmbito da corrente

4 Por mais que tentássemos encontrar a fonte da famosa frase referida, não tivemos êxito, o que nos faz suspeitar que se trate de tirada oral do nosso modernista quase lendário. que veio a chamar-se estudos culturais, tem lugar uma intensa discussão a propósito dos critérios para o estabelecimento do repertório das "grandes obras", ou seja, do chamado cânone. Segundo a perspectiva dos estudos culturais, o cânone - quer na sua versão clássica, vinculada às humanidades, quer na romântico-realista, comprometida com as nacionalidades, quer, 
5 Deve-se, naturalmente, relativizar bastante o esquema de sucessão linear que orientou nossa exposição, que terá sido não mais que recurso narrativo. $\mathrm{Na}$ verdade, menos do que sucessivos, os eixos que distinguimos são antes cumulativos, e a hegemonia de um deles, em certo período histórico, não significa exclusividade, pois, em todos os períodos, análise mais detida muito provavelmente identificará a vigência simultânea dos demais, ainda que em posições minoritárias. enfim, na modernista, promotora da literariedade - seria sempre uma construção assinalada por exclusões arbitrárias, cujas motivações políticas - inconscientes, na melhor das hipóteses, ou inconfessáveis, na pior - se ocultariam sob racionalizações de ordem crítica ou estética. Assim, humanidade, nacionalidade ou literariedade, como critérios para a seleção das "grandes obras", teriam conduzido a canonizações inaceitáveis, por seu efeito de homogeinização e, pois, por seu veto a tudo o que destoasse dos padrões de julgamento impostos.

Arvora-se então, como alternativa, a bandeira da diversidade; e a literatura, em vez de vista como linguagem densa e opaca, basicamente autorreferente, passa a ser concebida como transparência às diversas identidades não reconhecidas ou dominadas: a das mulheres, a das etnias politicamente minoritárias, a dos homossexuais, a das sociedades pós-coloniais. Desabilitam-se, assim, tradicionais conceitos unitários, como os de literatura universal e de literatura nacional, propondo-se como seus substitutos conjuntos articulados segundo o critério da diversidade, como, por exemplo, literatura feminina, literatura gay, literatura indígena, literatura afro-descendente, literatura pós-colonial. Enfim, segundo essa perspectiva, pressuposta a capacidade da literatura para a apreensão e a expressão das várias identidades psicossociais, seria seu papel exercer uma espécie de explícita pedagogia política, consagrada a persuadir o corpo social não só a tolerar as diversidades e conviver com elas, mas a preservá-las, valorizá-las e promovê-las, dada a riqueza sociocultural que representariam.

\section{6}

Se vale o modelo que propusemos, chama atenção a duração desigual dos vários eixos que atualizaram sucessivamente a confluência literatura / educação. ${ }^{5}$ Se o eixo humanidades cobriu mais de dois milênios - grosso modo, do classicismo ateniense às luzes do século XVIII -, o referencial nacionalidades não chegou a completar dois séculos, enquanto o princípio literariedade mal atravessou 50 anos. E o da diversidade, em evidência há pouco mais de duas décadas: na aceleração da história, quanto tempo lhe estará reservado? 


\section{REFERÊNCIAS}

AULU-GELLE. Les nuits attiques. Traduction nouvelle avec introduction et notes par Maurice Mignon. Paris: Garnier, s. d. BARTHES, Roland. Escritores e escreventes [1960]. In: ---. Crítica e verdade. Tradução de Leyla Perrone-Moisés. Revisão de Geraldo Gérson de Souza. São Paulo: Perspectiva, 1970. p. 31-39. BLUTEAU, Rafael. Vocabulário português e latino. Lisboa: Oficina de José Antônio da Silva, 1727. [V. 9 - Suplemento (Parte 1) - A-L]. FOUCAULT, Michel. As palavras e as coisas; uma arqueologia das ciências humanas. Tradução de António Ramos Rosa. Prefácio de Eduardo Lourenço \& Vergílio Ferreira. Lisboa: Portugália, s.d. [1966].

FREIRE, Luís José Junqueira. Elementos de retórica nacional. Rio de Janeiro: Eduardo

\& Henrique Laemmert, 1869.

GAMA, Miguel do Sacramento Lopes. Lições de eloquência nacional. Rio de Janeiro: Tipografia Imparcial de F. de Paula Brito, 1846. v. 1.

KANT, Immanuel. Da arte e do gênio (Crítica do juízo, § 4354) [1790]. Tradução de Rubens Rodrigues Torres Filho. In: ---. Crítica da razão pura; e outros textos filosóficos. Seleção de Marilena de Souza Chauí Berlinck. Tradução de Valério Rohden, Paulo Quintela, Rubens Rodrigues Torres Filho, Tânia Maria Bernkopf. São Paulo: Abril, 1974. p. 335-363.

MARROU, Henri-Irénée. História da educação na Antiguidade. Tradução de Mário Leônidas Casanova. São Paulo: E.P.U. / Edusp, 1973 [1948].

RODÓ, José Enrique. La enseñanza de la literatura [1908]. In: ---. Obras completas. Editadas por Emir Rodríguez Monegal. Madrid: Aguilar, 1957. p. 514-517.

ROMERO, Sílvio. A literatura brasileira e a crítica moderna. Rio de Janeiro: Imprensa de João Ferreira Dias, 1880.

-----. História da literatura brasileira. Rio de Janeiro: Imago; Aracaju: Universidade Federal de Sergipe, 2001 [1888]. v. 1.

SEVILLA, Isidoro de. Etimologías. Edición bilingüe. Texto latino, versión española y notas por José Oroz Reta y Manuel-A. Marcos Casquero. Madrid: Biblioteca de Autores Cristianos, 1993. 
SILVA, Antônio de Morais. Dicionário da língua portuguesa. 3. ed. Lisboa: Tipografia de M. P. de Lacerda, 1823. 2 v.

Dicionário da língua portuguesa. 4. ed. Lisboa: Impressão Régia, 1831. $2 \mathrm{v}$.

-----. Dicionário da língua portuguesa. 5. ed. Lisboa: Tipografia de Antônio José da Rocha, 1844. 2 v.

----. Dicionário da língua portuguesa. 6. ed. Lisboa: Tipografia de Antônio José da Rocha, 1858. 2 v.

----. Dicionário da língua portuguesa. 7. ed. Lisboa: Tipografia de Joaquim Germano de Sousa Neves Editor, 1877-1878. 2 v. SOUZA, Roberto Acízelo de. O império da eloquência; retórica e poética no Brasil oitocentista. Rio de Janeiro: Eduerj; Niterói [RJ]: Eduff, 1999.

-----. Iniciação aos estudos literários; objetos, disciplinas, instrumentos. São Paulo: Martins Fontes, 2006.

VERÍSSIMO, José. História da literatura brasileira. Rio de Janeiro: José Olympio, 1969 [1916].

\section{Abstract \\ The confluence literature/education: historical accomplishments}

The article characterizes the historical accomplishments of the confluence between literature and education, showing how the literary culture has been successively linked to the concepts of humanities, nationality, literariness and diversity.

Keywords: humanities; nationality; literariness; diversity. 